\title{
Inventory Control as an Effective Decision-Making Model and Implementations for Company's Growth
}

\section{Talatu Muhammad Barwa}

Department of Business Administration and Entrepreneurship, Faculty of Social and Management Science, Bayero University, Kano, Nigeria Email address:

talatubarwa05@gmail.com

\section{To cite this article:}

Talatu Muhammad Barwa. Inventory Control as an Effective Decision-Making Model and Implementations for Company's Growth. International Journal of Economics, Finance and Management Sciences. Vol. 3, No. 5, 2015, pp. 465-472. doi: 10.11648/j.ijefm.20150305.18

\begin{abstract}
The purpose of this study is to carry out research to analyse factors involved in inventory control decision process and its implementation for company's growth. The research is to be carried out through secondary data available in the perspective of the topic. The research centered on the concepts of inventory control decision-making process, and a detailed reports of different businesses implications of inventory control decision making process and its influence in company's growth and survivals in competitive environment. The theoretical details of the research assess some examples of some companies that have successfully achieved inventory control, which leads to minimum cost implications for holding inventory.
\end{abstract}

Keywords: Management, Inventory, Control and Company

\section{Introduction}

Since inventory represents one of the biggest numbers in a company's balance sheet, the effective inventory and control is a critical function to help indemnify the persistent and continued success of operational, distribution and manufacturing of modern business entities (Michalski, 2009, pp. 215-217). However, the effectiveness of inventory management and control is generally measured by how well a company is able to reduce its investment in inventory, achieve maximum throughput and meeting its customer service goals while containing its operational costs. On paper, however, the concept of inventory management appears to be relatively simple, it can be defined as a process that determines what inventory items needs to be stocked, how much of the stock needs to be held on hand and when should it be reordered and at what levels.

On the contrary, it is very complex in practice and its implementation within companies. The factors that cause this complexity fall into two broad classifications (Andersson et al., 2010, pp. 1519-1522). Firstly, there are conflict objectives across several distinct segments within a single company and the second factor lies in the uncertainty in the nature of its supply and demand. In light of this subject and baring these concepts in mind, the aim of this paper is to critically analyze the factors involved in inventory control decision-making process and its implementation within companies.

\section{Inventory Control}

Every company, whether in service sector or manufacturing, involves decision making of various kinds. At this point in time, we will discuss decision making related to inventory control and the factors involved in it (Andersson et al., 2010, pp. 1519-1522). Inventory control is also known as Stock control and the purpose of this is to monitor the stock at any given point in time. Not only this, but it also deals with the maintenance of the stock and keeping track of any excess or deficit. Inventory Control can be performed employing one of the many methods that are used by companies. All methods are efficient in their own right; a company must choose the one that suits it the most. It is not necessary for a company to go for just one method at a time, but instead it can be a mixture of two or more methods. Some of the methods that are popular among companies are as follows:

\subsection{Minimum Stock Level}

When a company chooses this inventory control method it basically fixes a minimum quantity reaching which, the company has to reorder and restock. As the minimum stock level signifies the minimum quantity at which the company has to reorder, this method is also known as Re-Order Level. 


\subsection{Stock Review}

This involves the review of stock regularly. The company keeps a check of the stock at regular intervals and at every review an order is placed for more stock to a pre-set level. This kind of method doesn't take into account the possibility of a sudden quick sale which is unforeseen and assumes the sales and the use up of stock to be in a monotonous pattern and hence the intervals are kept regular as nothing unpredicted is expected.

\subsection{Just in Time}

When a company decides to cut its costs by keeping the stock at a minimum, it arranges for the stock to be delivered as soon as and whenever the stock reaches its minimum point. This method involves running out of stock and a lot of dependency on the supplier as when the stock is at its minimum rate the company would need the stock immediately and so the supplier has to be such that he is always ready to deliver the stock whenever needed (Michalski, 2009, pp. 215-217). There is a lot of risk involved.

However, it is important to note that the above mentioned methods can be mixed with other types of processes to further improve the quality of stock control system's performance (Hua et al., 2011, pp. 179-182). These are briefly discussed below:

\subsection{Economic Order Quantity (EOQ)}

This is basically a formula that works for minimizing the total cost of inventory management overall, hence the title 'economic order quantity'. When a company wants to use the EOQ method to minimize the overall cost of inventory management, it uses the EOQ model which is: Total inventory costs $=$ Ordering costs + Holding costs

The first derivative of the function is taken to find out the equation for minimum cost:

EOQ $=$ SQRT $(2 \times$ Quantity $\times$ Cost per Order $/$ Carrying Cost per Order)

\subsection{Example}

XYZ Ltd. Sell footballs. Per order cost is $\$ 400$ and carrying cost per unit is $\$ 10$ annually. 20,000 units per year is the demand that the company has to cater to. Calculate the order size, total orders required during a year, total carrying cost and total ordering cost for the year.

\subsection{Solution}

$\mathrm{EOQ}=\mathrm{SQRT}(2 \times 20,000 \times 400 / 10)=1,265$ units

As the demand is 20000 unites per annum, the company will place exactly 16 orders i.e. $20,000 / 1,265$. Thus the total ordering cost is $\$ 64,000$ ( $\$ 400$ multiplied by 16). Average inventory being held by the company is $632.5((0+1,265) / 2)$ meaning the total cost of carrying is $\$ 6,325$ (i.e. $632.5 \times \$ 10$ ).

\subsection{Re-order Lead Time}

This allows the company to keep some time margin between placing the order and receiving it.

\subsection{Batch Control}

This requires managing the production in batches form. One must make sure that the components are right in number and will cover the needs until the initiation of the next batch (Hua et al., 2011, pp. 179-182). When the company can predict its needs, it is possible for it to order a fixed quantity of stock every time or even the order can be placed at fixed intervals which can be every month or every week or whatever suits the company.

\subsection{First in First out (FIFO)}

It is a method that makes sure the perishable items are used most efficiently so that there are no losses that incur. The stock is managed as per date received and identified date wise too and is taken through every stage of production depending on the first in first out concept.

\section{Inventory Decision Making}

Every business in the manufacturing industry and most businesses in the service industry require carrying out inventory. When inventory is a significant element of company, good management for it becomes necessary. Management as everyone knows, requires decisions to be made and if poor decision making is involved, the company can face losses, hence it must be done in a very organized and planned way.

Poor inventory management can cause sales to fall because of frequent stock outs i.e. when the company will keep running out of stocks, it won't be able to supply according to the demand and so their sales will fall (Alfaro \& Rabade, 2009, pp. 105-107). Similarly, the company might face insufficient production for some time due to certain circumstances. It implies that even though the company would be able to produce on full capacity, it won't because of its insufficient stock levels, poor decision making, poor inventory management etc. Moreover, operating expenses will increase due as there will be unnecessary carrying costs incurred because of discarding obsolete inventory. Additionally, the per unit cost of finished goods increases because of poor management as there is a lot of wastage in every process and so the cost increases overall effecting the per unit cost as well.

Creation of inventory is the most significant and definitely the most dynamic activity which is visibly done because inventory is a part of all activities related to production i.e. from purchasing of the raw materials all the way to the supply of the finished goods to the customer (Alfaro \& Rabade, 2009, pp. 105-107). Financial point of view puts down this issue in two perspectives; if the company manages its inventory poorly, it will affect the cash flow adversely, also it will be experiencing a lower rate of return, whereas, if the company over stocks its inventory, the statements will show larger total assets and hence the overall costs and expenses are likely to increase. 


\section{Factors Involved in Decision Making of Inventory}

Management involves keeping in focus a number of elements when in the process of decision making. It is a difficult task to decide the best quantity for inventory which does not adversely affect the cash flow or show larger amount of total assets and keeps the liquid assets low. The quantity should perfectly be in line with the demand of the product and the supply's capability of the company to make the best use of its capacity. Inventory management looks at a certain factors when considering the quantity. These factors include; order size, number of orders, safety stock, lead time, and planned production, suppliers of raw material, freight, production budget, purchasing cost and carrying cost. These are briefly discussed as follows:

\subsection{Order Size}

This defines the units of products per order (Caro \& Gallien, 2010 , pp. 260-263). Whether one order itself means a large quantity or whether only receiving a lot of orders means a large quantity is required to be produced. Another thing to be considered is that how frequently these orders come in.

\subsection{Number of Orders}

This tells about how many orders have been received at a given point in time.

\subsection{Safety Stock}

This is backup stock which ensures that the company would never run out of stock and will always have some reserve in times of need.

\subsection{Lead Time}

This is the margin between initiation of the order that placing the order and the arrival of the stock at the company i.e. receiving it. This has to be considered to keep enough stock for the lapse during the order processing.

\subsection{Planned Production}

Efficient planning and execution of production plans for the benefit of the company.

\subsection{Suppliers of Raw Material}

A company relies heavily on the suppliers of its raw materials. If they make the delivery late, the entire company can be affected and the estimated sales can fall drastically because of late delivery of inventory or failure. It is utmost important for a company to have some very reliable suppliers and well planned system to avoid any lapses during the order processing period.

\subsection{Freight}

The cost of inventory per unit might not be too high but its freight charges can make the overall package a little too pricey. The inventory management shouldn't just focus on the price of the inventory, but also its transportation as that can also cause for a large portion of the inventory expense. This is one of the reasons why companies usually set up their production units near the raw material productions and suppliers to cut down the overall cost of inventory and hence the total cost.

\subsection{Production Budget}

Good production budget can be made when the sales forecast is spot on. If the sales forecast isn't too dependable or valid, it won't be possible for the management to decide on the production process and hence the decision of production budget would also not be very accurate and might have a lot of loopholes (Caro \& Gallien, 2010, pp. 260-263). One has to know the demand to forecast the sales and then decide upon the stock levels, safety stock requirements, and most importantly the overall production budget. This element also plays a vital role as it determines what plant capacity is needed. The production budget at a certain point in time if exceeds the plant capacity during that time, then the capacity of the plant has to be increased.

\subsection{Purchasing Cost}

This aspect is somewhat covered in the production budget. The inventory management must try their best to get inventory at the best rates possible to keep the cost as low as possible. This in turn would make the profit margin bigger (Zhou \& Yu, 2011, pp. 515-517). The company can also lower down the prices of their products because of their low costs which in turn will attract more customers. Purchasing cost is basically the cost of placing order which consists of; purchase requisition preparing cost, purchase order preparing cost, cost of order delivery which includes postage, telephone calls, filing, etc., cost of inspection, receiving and storing i.e. cost of receiving purchased materials and voucher costs and accounting costs.

\subsection{Carrying Cost}

When a company purchases raw materials or manufactures goods, it needs to store these goods for the time till they are used or sold i.e. storage space is required. When the lot of the goods is big, there is a need for a bigger storage space as well. Another point to be considered is how long a particular batch of goods stay in the storage spaces (Zhou \& Yu, 2011, pp. 515-517). If the pace of production is faster than that of sales, the storage required has to be quite big to accommodate the incoming products. If inventory purchased isn't too big at a time, the space required should be reasonable.

Carrying costs that can be incurred either are; interest, where the bigger the size of the order, more the money will be needed for investment, storage costs, where manufactured goods and raw material both require some storage space which can be in the form of a building; a big warehouse etc. and have depreciation costs, taxes, where property tax is applied on the inventory, insurance, where in case of any unforeseen incident 
like fire etc. insurance covers up for losses. But these things don't always take place and hence mostly these add to the costs of the company, spoilage and salary of the warehouse/storekeeper and of the help if any.

\section{Factors Affecting Inventory Operations}

In today's business environment, an increasing number of inventory operations are being outsourced by organizations to third party service providers in an attempt to ensure that costs and investments in inventory management are effective reduced. This is a common trend that has developed in recent years, provided that organizations focus on reviewing and overseeing both inventory operations as well as inventory management periodically to guarantee effective controls are maintained decision making processes are followed and implemented within companies.

Specifically, the management of inventory comprises of a study of the movement of inventory or stocks, its ordering time, its demand patters, cycles of its supplies and sales flows. In light of these there is a need to actively manage inventory through continuous management of inventory items and its analysis in order to direct the company towards a lean inventory management (Zhou \& Yu, 2011, pp. 515-517). It is the inventory planers within the company who have the responsibility to manage the inventory management function in a manner that is closely aligned with supply chain logistics and finance, and procurement apart from marketing departments.

However, the efficiencies of such functions are highly dependent on the knowledge, skills and aptitudes of inventory planners, the inventory management systems itself coupled with the focus and involvement of the management and its related policies. However, in certain cases inventory operations management and its control lies under the authority and supervision of third party service providers and not rests within the control of the inventory management team. There are a few action points and critical areas on part of such outsourced operations that can have a significant impact on the inventory management of the organization. Primarily these include; the unskilled labor and staff and an inadequate standard operating procedure (SOP), training and emphasis on process compliance. These are briefly discussed as follows:

\subsection{Unskilled Staff and Labor}

The management of inventory operations is a process oriented operation. Every action and task requires execution by the operatives who will have an impact on delivery lead times, inventory along with other parameters. This is why it is imperative that the person or the operative has sound knowledge of his or her operational responsibility and understands the effect of its actions on the floor. For instance, if an individual or an operative is given a task to put away an essential component, than he or she needs to know how to keep it, where to keep it, how to scan it and confirm it with the inventory system. Similarly, he or she should also know the likely impact of not doing or performing any of these actions and or if done wrong. Moreover, the operative must also be clear on the likely impact of his or her action on the physical inventory as well as on the system.

Secondly, it is also important to note that different inventory items need to be handled differently. In light of this, the inventory operative needs to know what is required of them to the carry out the task and in what manner. Moreover, they also need to know about the likely consequences if they fail to adhere to the process and what is required of them. For instance, inventory in the form of cartons might have to be opened and scanned for distinct boxes inside whereas a pallet might have to be scanned for the pallet id and put away on a floor location. Therefore, inventory operatives must be trained regarding the entire process in order to understand what they are doing and why.

Similarly, warehouse management systems (WMS) are quite task and operational intensive. Therefore, during times when the warehouses are being managed through systems based on RF, inventory management operatives should have the necessary skill set, knowledge and aptitude to be able to manage RF readers, complete transactions through the application of RF Guns and understand how to access it. However, it has been found that when warehouse based operations are managed by third party service providers and in the absence of the principal customer on the location the quality of operations and staff is often compromised. This is due to the fact that such people are not being provided with adequate trainings before being assigned with the responsibility. This leads to discrepancies in inventory management and operations.

\subsection{Inadequate SOP, Training and Processes Compliance}

In situations where projects of inventory management are being handled, administered, operated and monitored by third party warehouse location, it is both the third party service provider and the principal customer who work on the project and establish its operational processes, conduct trainings and document Standard Operating Procedures (SOP) as part of the management methodology of their projects. However, periodically there are changes in the nature of business requirements that causes change in operating processes. Therefore, such changes very often do get documented timely in terms of the amendments and consequently the SOPs become obsolete. Subsequently, what happens is that when new comers are introduced to the operational floor, they are obliged to learn and work along with others but do not have the SOP documents or trainings provided to them that they could use for reference.

As a result, inventory management operatives are given with incomplete process knowledge and carry out tasks not realizing what they are doing, how they are doing it and what they are required to do. Such a situation is very risky for the health of inventory and this behavior represents lack of professionalism on part of the third party service provider. However, if such trend continues then it is likely to result in 
discrepancies, inventory mismatches, bad housekeeping and also adversely affect the service delivery. Moreover, in some situations this may also lead to pilferage, misuse and theft of inventory. However, in order to overcome the issues that are brought about following the ownership of inventory operations warehouse by a third party, the principal client needs to ensure that proper trainings and periodic review is conduct for the entire staff employed in inventory management. Moreover, inventory counts and audits need to perform on a regular basis and inventory operations must be reviewed periodically.

\section{Inventory Control Decision Making}

There are several factors that make company decisions pertaining to inventory control and its management very difficult and a challenging task for inventory managers. However, there are two broad factors that contribute towards this complexity; conflict objectives and uncertainty in its supply and demand. In the case of the former, there are some segments of the business that seek to increase their stocks of inventory, whereas some seek to decrease them (Huang \& Chen, 2009, pp. 6470-6473). For instance, because the sales department wants to ensure the delivery of their product to the end consumer in order to satisfy their customer's demand in the best time possible, they demand the company to keep stocks or inventory of finished products on a high. Similarly, the purchasing department is willing to pursue off-season purchases and in large quantities in order to achieve a bulk discount which again increases inventory and the same goes for the production department.

On the other hand, the finance department and product developers want to keep the levels of inventory low in order to increase the distribution of their new products. Moreover, as a matter of extreme importance, the upper management wants to decrease inventory levels in order to keep their cash flows liquid. However, it is important to note that both these departments are working for the same goal; to improve profitability but have difference in their opinions regarding how to achieve these goals. Likewise, there are difficulties that arise due to the uncertainty and unpredictability of the inventory supply and demand. For example, shrinkage, obsolescence of products, perishability, and scarcity of materials, supply chain disruptions and unsteady supplier performance contribute to the establishment of buffer stock in order to capitalize and provide safety of lead time supply.

However, on the demand side of things, new products and innovations, the overall economic environment, the sporadic seasonal sales traffic and high traffic sales volume for other compel the organization to establish a mixed approach. For company manufacturers and distributors, these factors become highly complicated when thousands and thousands of goods for sale are located in several warehouses across multiple locations. However, in spite of these complications, inventory management and control still essentially represents a fine line between stocking the least amount of inventory possible and meeting the diverse customer needs and expectations (Lee et al., 2009, pp. 25-29). Being lifeblood to the production and sales processes, it is imperative for inventory managers to stock enough to avoid issues such as loss of customer satisfaction and loyalty or diminishing sales.

Nonetheless, since stocking inventory is very expensive, it is imperative to store leaner inventory quantities in order to circumvent carrying costs such as storage, security, insurance and taxes and to prevent any opportunity cost from occurring in terms unavailable funds for running finance (Curcio \& Longo, 2009, pp. 279-282). Regardless, inventory is typically one of the biggest assets for a company and research strongly suggests that the management of inventory is an area that requires significant improvements for the utmost efficiency of manufacturers and distributors (Stanger et al., 2012, pp. 155-157). For instance, Aberdeen Research Group in a survey of supply chain professionals in the year 2012 revealed that more than 60 percent of the respondents stated that minimizing inventorial costs was their top priority, whereas an approximate 42 percent of the respondents indicated that they prioritized their customer service above anything else.

\section{Inventory Control as a Multifunctional Process}

In order to analyze the factors that are involved in the inventory control decision making process there is a need to understand how the inventory control process works. The effective inventory control and management is entrenched in three distinct yet interlinked processes. These are briefly discussed below:

\subsection{Physical}

This process pertains to the physical nature of inventorial control. It implies that stocking, movement and receiving along with the overall physical control of a company's inventories. This component of inventory management is ongoing in larger and mid-market companies with shipments departing and arriving numerous times a day (See \& Sim, 2010, pp. 585-589). Kit repackaging, consigning, bar-coding stock keeping units (SKUs) are distinct aspects of physical control of inventory. Moreover, this process also includes the responsibility of data entry and its physical control on a day to day basis.

All of the company's inventory items that are moved in and out of the inventory system are tracked through the organization's Enterprise Resource Planning (ERP) systems. However, it is imperative to keep a timely and accurate collection of the data (Mitra, 2012, pp. 872-874). Furthermore, inventory specialists also pursue perpetual physical inventory (PPI) or a strict schedule of cycle counting. This allows companies to manually intervene and verify that computerized data records with regards to the quantity and location of the stock is aligned and manifested through the physical stock.

\subsection{Planning}

Physical inventory focuses on the movement and control of 
a company's stock, while the inventory planning focuses on its systematic management. The ordering and planning of inventory is heavily dependent on numerous methodologies that further depend on the changing rates of demand. This is why a vast majority of companies make use of material requirements planning (MRP) in scenarios that involve sales of high volume, or like in just-in-time or kanban in lean environment (See \& Sim, 2010, pp. 585-589). To put it simply, the MRP systems allows the inventory to be right-sized that gets replenished frequently and turned over reliably. Right-sizing implies lost in sales of items that are highly demanded and avoiding stock-outs and trapping of the working capital.

The JIT inventory management system bases the purchases of new materials and stock as per the needs and requirements of the customer in an ongoing basis. For example, organizations that assembles or sells only a limited number of items being large in nature on an annual basis do not require such inventory management systems (See \& Sim, 2010, pp. 585-589). However, in situations that are both high and low in volume, the stocking of inventory and its accuracy is driven by conscientious data entry. Whether the stock is ordered through irregular special deliveries or through regular truckloads, the preplanned and systematic approaches for inventory replenishment utilize information that is relevant to purchasing, finance, sales, shipping, receiving and possibly production. This interplay of information occurs due to the effective implementation of ERP systems that leads to much greater efficiency.

\subsection{Optimization}

Regardless of best efforts to systematically plan stock-outs and inventory ordering, stock overages inevitably occur. The frequent occurrence of stock overages and stock-outs imply that inventory levels are not being optimized. This calls for an inventory optimization system. The advent of supply chain management mechanisms and related technologies make use of arithmetical calculations and determine when and where inventory needs to be deployed in order to fulfill the predetermined quantities (Dooley et al., 2010, pp. 13-17). Such mechanisms are designed to effectively classify multiple stocking levels on the basis of the analysis put forth through preceding demands and support the management of suppliers on the basis of their recent performances while improving the forecasting of anticipated demand.

However, the latter provides with the greatest implications for inventory level optimization. This is because stock overages and stock-outs all breed from a mismatch between the demand of the stock and the stock that the company actually has in hand. Although, inventory specialists can possibly not eradicate such discrepancies entirely, but with the emergence of inventory optimization technology, there is hope of minimizing such mismatches to a great degree (Dooley et al., 2010, pp. 13-17). These new mechanisms allow inventory managers to forecast demand more accurately and with much accuracy and speed in order to effectively satisfy the predetermined inventory quantities that will satisfy inventory management and control objectives. However, this time, the objectives of maximized throughput, increased customer satisfaction, quantifiable reductions in inventory investment and minimization of costs well within the reach.

\section{Forecasting and Analyzing Tools}

Analytical tools and instruments such as production data, supplier information, financial data, purchasing and longitudinal sales allows ERP systems to make full use of these variables and their relevant information in order to produce reports that represent each of these data sets, both individually and collectively (Lee et al., 2009, pp. 25-29). These reports comprise of graphical illustrations and charts that allow inventory managers to compare and contrast results against the key performance indicators of the industry from time to time. Consequently, business managers are able to fine-tune their best practices, build on their successes, strengthen their core competencies, resolve problems and are able to make effective and timely decisions on the basis of such valuable reports.

\subsection{Analysis}

The effective integration of the existing ERP system with an inventory optimization tool allows managers and inventory specialists to take the functionality of their data analysis a great step further (Schwartz \& Rivera, 2010, pp. 113-115). For instance, the effective utilization and implementation of proprietary algorithms allows business managers to develop and provide a graphical interface that clearly illustrates the synthesized data from all of the company's departments. This synthesis would diagnose, analyze and identify the seasonal shifts in the demand of distinct items, the patterns of production downtime, the patterns of optimal and suboptimal supplier performance, the patterns of volume discounts and price reductions from suppliers, the identification of unsellable items in need of disposal, the identification of items that are moving too slowly and can lead to draw downs, excess orders, lost sales, when the stock-outs and overages are likely to occur, the identification of patterns for large customer orders and the identification of concomitant periods of tensed overall organizational cash flow and so on.

\subsection{Forecasting}

Following the analysis illustrated above, the inventory optimization tool consequently uses this cross-functional huge data analysis as a means to forecast the likely demand in a manner that is much accurate and faster than it was before (Gumus \& Guneri, 2009, pp. 5567-5569). This allows the system to suggest inventory levels that are optimal for the availability of sales, while taking into consideration the risks of potential overages and stock-outs and to allow inventory specialists with timely warnings pertaining to levels of stock that are approaching numbers that are too low or too high.

\subsection{Management}

Following the effective forecasting illustrated above, the 
inventory optimization tool also provides suggestions regarding the schedules for optimal restocking while also providing thresholds on a unit levels for the automated replenishment and ordering of inventory within companies (Schwartz \& Rivera, 2010, pp. 113-115). One of the primary features of this system is its ability to identify exceptions and notify the management when mitigation is necessary. Moreover, due to the fact that this optimization tool is incorporated within the current ERP system, the exception alerts, automated orders, replenishment schedules, and suggested stock levels are effectively communicated cross-functionally as well as to stakeholders that are external to the organization, thereby implying that an inventory optimization tool makes effective and promising use of actionable intelligence.

\section{Optimized Inventory Levels Decisions}

The degree to which inventory levels are optimized are highly dependent upon the decisions of senior management and inventory specialists on the basis of numerous considerations that are distinct and unique to their own companies and inventorial operations. The use of sophisticated tools within the decision making process helps inventory managers effectively and accurately balance the trade-offs between the costs of over-stocking versus the costs of a stock-out (Gumus \& Guneri, 2009, pp. 5567-5569). This implies that ability of the inventory management tool to align suggested levels of stocking is reliant on the tolerance of risks that come to focus.

For example, the sales data analysis may identify that the profit per unit is far more then the inventory investment which is an unbalanced dependence on the repeat of clients that offer high volume or that additional streams of revenue are opened following the each sale of a unit. Such factors force the hand of managers to drive their risk tolerance levels towards a direction that does away with stock-outs allowing more readily available inventory. On the contrary, there are certain companies that stock perishable items which are highly expensive to maintain and store (Gumus \& Guneri, 2009, pp. 5567-5569). Moreover, the economic conditions also have a major role to play in decisions pertaining to inventory management by requiring a company to generate additional working capital.

This is a situation that personifies the modern business environment. It is these factors that often compel the management to stock minimum levels of inventory to minimize their sizable costs of storage. Nonetheless, it is the fundamental responsibility of inventory management to make decisions that are better and lead to a more equivalent trade-off, depending on the ever changing goals that are influenced by realities on the ground (Curcio \& Longo, 2009, pp. 279-282). Moreover, when such sophisticated and innovative tools are made available to inventory managers, it facilitates the improvement of trade-off balances and help companies generate ongoing and large returns on investment.

For instance, if a distributor has carried inventory worth of
$\$ 60$ million and has effectively made use of an inventory optimization tool that has allowed him to reduce his inventory levels by a mere 5 percent and has been able to maintain the satisfaction of his customers, then he has successfully added $\$ 3$ million of his working capital in his financial accounts (Lee et al., 2009, pp. 25-29). However, certain companies tend to reduce their levels of inventory much further. In a report published by WSJ.com, it was stated that the best supply organizations make a highly proficient use of sophisticated analytical tools in an attempt to minimize their inventory levels by a staggering 20 to 50 percent that allows them with savings that lasts for years and years.

\section{Conclusion}

The aim of this paper was to critically analyze the factors involved in inventory control decision-making process and its implementation within companies. On the basis of the literature reviewed and analyzed it is safe to conclude that even though the right-sizing and effective management and control of inventory is a complex and challenging task, but due to the increasing pressure being placed by the top management to minimize costs and increase customer satisfaction, inventory managers are swiftly moving towards the adoption and implementation of advanced and sophisticated inventory management systems that allow them to mitigate the factors involved in the inventory control decision making processes that contribute towards high inventory costs.

The aim of this paper is to critically analyze the factors that are involved in inventory control decision-making process and its implementation within companies.

\section{References}

[1] Alfaro, J. A., \& Rábade, L. A. (2009). Traceability as a strategic tool to improve inventory management: a case study in the food industry. International Journal of Production Economics, 118(1), 104-110. Retrieved from: http://www.sciencedirect.com/science/article/pii/S0925527308 002533.

[2] Andersson, H., Hoff, A., Christiansen, M., Hasle, G., \& Løkketangen, A. (2010). Industrial aspects and literature survey: Combined inventory management and routing. Computers \& Operations Research, 37(9), 1515-1536. Retrieved from: http://www.sciencedirect.com/science/article/pii/S0305054809 002962 .

[3] Caro, F., \& Gallien, J. (2010). Inventory management of a fast-fashion retail network. Operations Research, 58(2), 257-273. Retrieved from: http://pubsonline.informs.org/doi/abs/10.1287/opre.1090.0698.

[4] Curcio, D., \& Longo, F. (2009). Inventory and internal logistics management as critical factors affecting the supply chain performances. International Journal of Simulation and Process Modelling, 5(4), 278-288. Retrieved from: http://inderscience.metapress.com/index/452475h453k85736.p df. 
[5] Dooley, K. J., Yan, T., Mohan, S., \& Gopalakrishnan, M. (2010). Inventory Management And The Bullwhip Effect During The 2007-2009 Recession: Evidence From The Manufacturing Sector*. Journal of supply chain management, 46(1), 12-18. Retrieved from: http://onlinelibrary.wiley.com/doi/10.1111/j.1745-493X.2009. 03183.x/full.

[6] Gumus, A. T., \& Guneri, A. F. (2009). A multi-echelon inventory management framework for stochastic and fuzzy supply chains. Expert Systems with Applications, 36(3), 5565-5575. Retrieved from: http://www.sciencedirect.com/science/article/pii/S0957417408 004132 .

[7] Hua, G., Cheng, T. C. E., \& Wang, S. (2011). Managing carbon footprints in inventory management. International Journal of Production Economics, 132(2), 178-185. Retrieved from: http://www.sciencedirect.com/science/article/pii/S0925527311 001599.

[8] Huang, Q., \& Chen, J. (2009). A note on "Modelling an industrial strategy for inventory management in supply chains: the 'Consignment Stock' case". International Journal of Production Research, 47(22), 6469-6475. Retrieved from: http://www.tandfonline.com/doi/abs/10.1080/0020754080227 5863.

[9] Lee, Y. M., Cheng, F., \& Leung, Y. T. (2009). A quantitative view on how RFID can improve inventory management in a supply chain. International Journal of Logistics: Research and Applications, 12(1), 23-43. Retrieved from: http://www.tandfonline.com/doi/abs/10.1080/1367556080214 1788 .

[10] Michalski, G. (2009). Inventory management optimization as part of operational risk management. Economic Computation and Economic Cybernetics Studies and Research, 213-222.

Retrieved

from: http://papers.ssrn.com/sol3/papers.cfm?abstract id=1562699.

[11] Mitra, S. (2012). Inventory management in a two-echelon closed-loop supply chain with correlated demands and returns. Computers \& Industrial Engineering, 62(4), 870-879. Retrieved from: http://www.sciencedirect.com/science/article/pii/S0360835211 003810 .

[12] Schwartz, J. D., \& Rivera, D. E. (2010). A process control approach to tactical inventory management in production-inventory systems. International Journal of Production Economics, 125(1), 111-124. Retrieved from: http://www.sciencedirect.com/science/article/pii/S0925527310 000216 .

[13] See, C. T., \& Sim, M. (2010). Robust approximation to multiperiod inventory management. Operations research, 58(3), 583-594. Retrieved from: http://pubsonline.informs.org/doi/abs/10.1287/opre.1090.0746.

[14] Stanger, S. H., Yates, N., Wilding, R., \& Cotton, S. (2012). Blood inventory management: hospital best practice. Transfusion medicine reviews, 26(2), 153-163. Retrieved from: http://www.sciencedirect.com/science/article/pii/S0887796311 000897.

[15] Zhou, S. X., \& Yu, Y. (2011). TECHNICAL NOTE-Optimal Product Acquisition, Pricing, and Inventory Management for Systems with Remanufacturing. Operations Research, 59(2), 514-521. Retrieved from: http://pubsonline.informs.org/doi/abs/10.1287/opre.1100.0898. 